\title{
Overview of current diagnostic, prognostic, and therapeutic use of EEG and EEG-based markers of cognition, mental, and brain health
}

\author{
Priya Miranda ${ }^{1}$, Christopher D Cox ${ }^{2}$, Michael Alexander ${ }^{1}$, Slav Danev ${ }^{3}$ and Jonathan RT Lakey ${ }^{*}$ \\ ${ }^{1}$ Department of Surgery and Biomedical Engineering, University of California Irvine, California, USA \\ ${ }^{2}$ Department of Neurology, David Geffen School of Medicine, University of California, Los Angeles, California, USA \\ ${ }^{3}$ Medeia Inc, Santa Barbara, CA, USA
}

\begin{abstract}
The global burden of cognitive, mental, neurological, and substance-use disorders at 258 million disability adjusted life years calls for immediate "action" in their prevention and management. The electroencephalogram (EEG) is one of the most widely-used instruments for the non-invasive neuro-physiological measure of brain function and health. The EEG was originally used to solely monitor and record electric waves generated by electrical activity in the brain to aid in clinical decision-making and diagnosis. Technological improvements have made it possible for state-of the-art EEG computer-based systems like NeuralScan by Medeia Inc. to evaluate changes in power and in ratios of these brain waves with changes in brain and mental health status. Today's EEG machines can also identifying the precise localization of these changes enabling more accurate diagnosis and treatment. Improvements in EEG technology have made them robust, stationary/portable, high fidelity, versatile with the ability to carry out complex functions and calculations yet still be user/clinician-friendly highlighting their potential for use in clinical, research, epidemiological and public health settings. The present article presents an overview on EEG machines, their use in diagnosis, prognosis and therapy and to generate EEG-based markers in the area of cognition, mental and brain health.
\end{abstract}

\section{Introduction}

\section{EEG in brain health and cognition}

Normal functioning of the cerebral cortex is critical to physiological, neurological and mental health. Currently, cognitive, mental, neurological, and substance-use diseases/disorders account for 258 million disability adjusted life years (10.4\% total all cause DALYS). This reiterates the need for better prevention, diagnostic and treatment options for brain health that can be used in clinical, epidemiological and public health settings [1-2]. Among the diagnostic and assessment tools for brain health are the a) non-invasive: neuro-clinical-physical examinations, questionnaires /instruments, electroencephalogram EEG, neuroimaging including ultrasound, magnetic resonance imaging, MRI, functional MRI (fMRI), positron emission tomography (PET), and computerized tomography (CT); and b) the invasive: biochemical tests, genetic tests, cerebrospinal fluid (CSF) analysis, angiography, and biopsies. While the MRI, fMRI, PET and CT provide good spatial resolution of brain health, the EEG evaluates brain health via temporal resolution of brain function within the millisecond range [3-5], which is not possible with the other approaches. Due to its sensitivity to changes in brain function and structure and its simplicity of use in clinical settings, its use in intensive care has continued to increase in recent years [6-8].

The EEG assesses the neurophysiological aspects of brain function via the capture of the electric waves generated by electrical activity in the cerebral cortex. The cerebral cortex is divided into four lobes: the frontal, parietal, temporal and occipital; each of which performs specific functions. The $4 \mathrm{~mm}$ thick cerebral cortex was mapped out by
Brodmann based on cytoarchitecture, histology and function into 52 Brodmann's areas (BA). Twenty-six BA are of current interest in neuroelectrophysiological studies on brain and mental health. The normal brain waves emitted by the cerebral cortex based on their electrical activity are the Alpha $(\alpha)$ at $8-15 \mathrm{~Hz}$, Beta $(\beta)$ at $16-30 \mathrm{~Hz}$, Gamma $(\gamma)$ at 31-100 $\mathrm{Hz}$ with low gamma at 30-70 $\mathrm{Hz}$ and high gamma at 70$150 \mathrm{~Hz}$ and the Sensorimotor rhythm (SMR) at 13-15 Hz. The power and the ratio of these waves vary with regions of the cerebral cortex, the task at hand and different mental states. The morphology, power and ratio of these waves are used today to classify normal and abnormal brain function as well as in diagnosis, prognosis and therapy. Today's EEG machines allow precise localization of the normal/abnormal wave form in the brain and in turn which BA areas are involved enabling the clinical decision-making process.

\section{EEG as a diagnostic, prognostic and therapeutic tool}

Indications for monitoring using EEG include seizure disorders such as epilepsy [9-13], traumatic brain injury [14-17], stroke [1824], encephalitis [25-27], brain tumor [28], encephalopathy [29-31], memory problems [32-33], sleep disorders [34-35], coma [36-39],

*Correspondence to: Jonathan RT Lakey, Department of Surgery, 333 City Blvd West, Suite 1600, Orange, CA 92868, USA, Tel: 1-949-824-8022; Fax: 1-714456-6188; E-mail: jlakey@uci.edu

Key words: electroencephalogram, qEEG, LORETA, neural imaging, diagnostics, neuralscan

Received: July 22, 2019; Accepted: August 06, 2019; Published: August 13, 2019 
cardiac arrest [40], diagnosis of brain death [41-42] and dementia. In recent times EEGs have also been used to study Alzheimer's disease (AD) [43-44] and other forms of dementia [45-46], multiple sclerosis [47-49], pain disorders [50-51], Parkinson's disease [52-55], migraines [56-58], and behavioral disorders such as attention deficit hyperactivity disorder (ADHD) [59-61], autism [62-64], depression [65-67], post-traumatic stress disorder [68-71], complex developmental trauma disorder [72] and substance abuse [73-75]. With the advent of neurofeedback EEG became viable as a treatment option, being used for performance enhancement (academic, athletic or mental), and as treatment for ADHD, autism, Alzheimer's, post-traumatic disorders and substance abuse [76-80]. Thus since 1924 [81], the EEG has evolved from being an add-on tool in the diagnosis of brain health, to an instrument that is used for diagnosis, disease-staging [82-88], evaluation of prognosis including during the course of treatment (pharmacotherapy and chemotherapy) [89-93], and as itself as a therapeutic tool [76-80].

\section{EEG: Aiding diagnosis, preventing misdiagnosis and under- diagnosis}

EEG has recently been used in the differential diagnosis of syndromes of uncertain etiology [94-97]. For example, subcortical ischemia or multiple infarcts or single strokes have been known to cause personality changes, affective disorders, and even psychosis. Similarly, psychiatric disorders such as obsessive compulsive disorder (OCD), schizophrenia, autism, dyslexia, and addictions have shown distinct differences in neurological features between subjects and controls. The EEG is also useful in distinguishing diseases with similar symptoms yet different etiopathophysiology. Cognitive impairments, for example, can be due to a range of reasons like electrolyte imbalance, hypoglycemia, sleep disorders, stress, head injury, pain, dementia, etc. [94].

Recently the EEG's potential to generate either early diagnostic markers or biomarkers has been explored for neurological disorders like AD [43-44], multiple sclerosis [47-49], Parkinson's disease [5255], schizophrenia [98], autism [62-64], and dyslexia. A study on neurodegeneration and progression from mild cognitive impairment (MCI) to fully developed AD revealed significantly higher levels of delta bands among AD subjects, for example [84]. A 2-year longitudinal study on $86 \mathrm{MCI}$ patients used six EEG biomarkers to successfully predict the conversion of 25 patients exhibiting beta activity to $\mathrm{AD}$ with $88 \%$ sensitivity and $82 \%$ specificity [86]. Automatic feature extraction techniques helped predict focal seizures increasing the sensitivity to $87.8 \%[88]$.

\section{Current EEG technology in a nutshell}

The design, specification, maintenance and calibration protocols for electrodes [99-109], electrode placement systems [109-118], use of ground and reference electrodes, EEG machines (analog, digital or multi-channel), EEG calibrators and montages [119] are governed by stringent standards and guidelines [120-129]. EEG recording procedures are categorized into two stages: a) data acquisition and pre-processing, and b) feature extraction. The stages are performed as follows:

Acquisition and pre-processing: The EEG captures the pyramidal neuronal activity comprising action potentials $(3 \mathrm{~ms})$ and postsynaptic potentials (200ms) via electrodes following an excitatory stimulus [98]. The $20 \mu \mathrm{V}$ signal is amplified using a differential amplifier, followed by normal amplifiers. High-pass (HPF), low-pass (LPF) and notch filters are then used to minimize/overcome/nullify "noise" arising from intrinsic and extrinsic factors, and the distortion caused by aliasing when the analog signal is digitized by the analog-to-digital converter [122-128].

Artifact correction: Correction for artifact removal or attenuation is carried out depending on the data and study design. Artifacts due to eye blinks or head shaking which are symptoms are attenuated and not removed. ICA (Independent Component Analysis) and SSP (Signal Space Projection) are some of the methods used for artifact attenuation [130-133]. Signal averaging, thresholding of the output, signal enhancement, and finally edge detection are then carried out.

Data processing: Processing of data includes feature extraction, selection and classification. In general for most digital EEG machines, feature extraction alone is carried out. Fast Fourier Transform (FFT), Wavelet Transform (WT), Time-Frequency Distributions (TFD), and Foreword and Inverse Source Space analysis are among the methods used for feature extraction [133-137]. Patient data is then stored for neuroclinical assessment and report generation [138-140].

\section{Software developments in EEG technology}

Previously, the patterns of EEG wave forms/wave morphology alone were used in combination with other neurological tests to diagnose neurological disorders [141-143]. In more recent years the processed EEG data (wave forms) are quantified via quantitative EEG (q-EEG), wherein a specialized software program converts 1-dimensional (1-D) brain wave signals into 2-D topographical color maps comparing a patient's brain function to a normative database (Neuroguide, FDA research standard) [144-146]. The resulting color code allows for the generation of quantitatively relevant $\mathrm{Z}$-scores. Another software development that revolutionized the field improving the spatial resolution of EEGs was the use of Independent Component Analysis (ICA) in combination with Low Resolution Electromagnetic Tomography (LORETA) [145-153] to transform 2-D into 3-D EEG data, which enabled locating the source of EEG waves on the cortical lobes. Source location (originally only possible via CT or MRI) is important as it enables identification of the functional regions involved in specific responses or disease states.

Figure 1 shows the components of the NeuralScan by Medeia a state-of the-art EEG computer-based system. It is in keeping with current standards and incorporates the most up-to-date technological improvements in the field of EEG machines. Figure 1A shows the 21-channel EEG cap. The built-in software can carry out routine clinical assessment of EEG wave forms (alpha, beta, theta or gamma) and wave forms tests, namely; resting-state EEG (eyes closed and opened). Or, the system can evaluate working memory and ERPs (Figure 1B) from evoked potentials (visual, auditory, odd ball paradigm) and behavioral motor tests. The system is capable of i) "automatic" artifact (blinks, pulse artifact, MR gradient artifact, ballisto-cardiogram, and bad blocks) removal via FFT, wavelet and ICA as well as ii) feature extraction, iii) frequency-based analysis of the EEG wave forms and iv) for transformation from the time domain to the frequency domain. The software can also perform qEEG for brain mapping, power and frequency analysis and comparison with a normative database provided with the package (Figure 1C) and with eLORETA to carry out source analysis (Figure 1D). Also provided with it is a neuropsychological questionnaire with some sections that the patient answers (self-reporting) and others that the clinician administers. The test takes in total 15 minutes to perform. The reporting system can be customized to make summarized reports that can be easily understood by physician and patient (Figure 1E), or detailed reports that can depict correspondence of EEG and vital signs (Figure 1F). 


\section{EEG-based markers of cognition, mental and brain health}

Normal EEG wave forms [154-156] vary with age, mental states and depending on if they are stimulus induced or resting-state. Abnormal wave form patterns [126,157] are subdivided into epileptic and generalized non-ictal wave forms and include: intermittent slowing, intermittent rhythmic delta activity (IRDA) continuous slow activity (diffuse slowing, alpha coma), periodic abnormalities (Burst suppression, periodic discharges (GPDs/SIRPIDS), and background suppression. Disease-specific patterns are also observed. For example, disease-specific EEG patterns have been noted in subacute sclerosing panencephalitis (SSPE) [158] and in Creutzfeldt-Jakob disease [159].

The processed EEG wave forms captured at a) resting-state EEG (eyes closed and opened), b) following a specific task (working memory) and c) event related potentials (ERPs) including evoked potentials (visual, auditory, odd ball paradigm) are the source of several brain health biomarkers [160-162]. Figure 1 summarizes wave types that can be used in EEG to provide information on neurological and mental health EEG-generated markers that have been used in both neurological/mental health research and for clinical assessment.

\section{Event related potentials (ERPs) in disease and research}

Evoked or event-related potentials (ERPs) are obtained following an event/stimulus. The stimulus can be visual, auditory, motor or task related. Checker-boards with black and white squares with the black and white squares alternating their positions at a predefined period are often used as visual stimuli. They are presented on a computer screen for a specified duration, and as the brain is able to recognize the interchange in black and white squares within a fraction of a second; this recognition is captured in an EEG wave form. The epochs that capture one complete stimuli and response cycle are marked out and selected. As the stimulus/test duration may be 5 minutes. All the epochs pertinent to that duration and stimulus are similarly marked and selected. The averaged response to a particular stimulus provides the event-related potential (Figure 1D) for that stimulus. The ERP waveform has both positive and negative components which are denoted as " $\mathrm{P}$ " and " $\mathrm{N}$ "

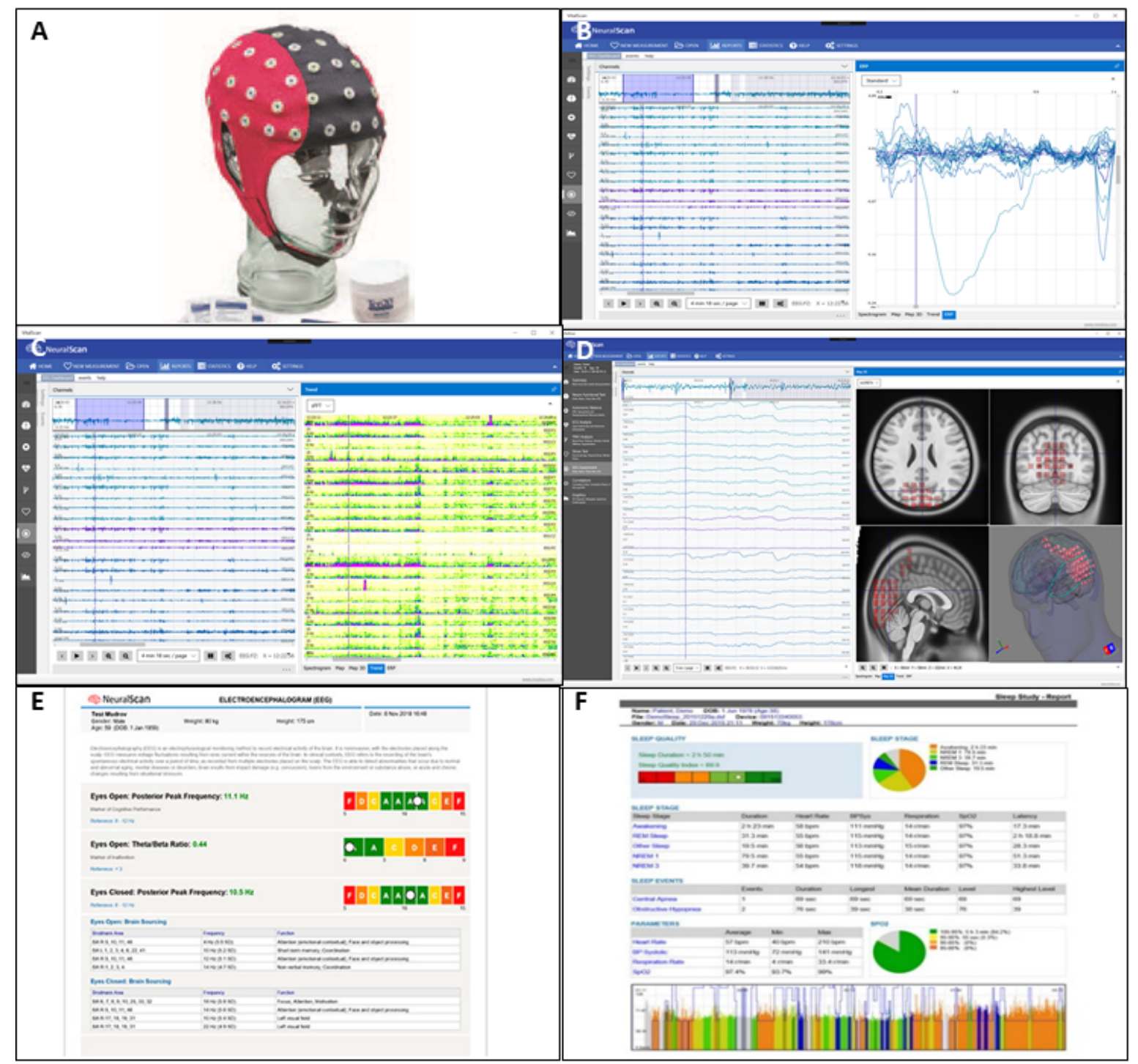

Figure 1. Components of Neuralscan by Medeia. (A) 21-Channel electroencephalograph (EEG) cap; (B) Signal averaging for event related potentials (ERP) generation; (C) Power analysis, frequency analysis, and QEEG mapping; (D) Source localization via exact low-resolution electromagnetic tomography (eLORETA); (E) simple report; (F) full report with time correspondence to vital signs reading 
respectively with a number (P100 and N100) that either indicates the latency in milliseconds or the hierarchical position of the wave form.

In an ERP study of schizophrenic patients, P100 amplitude principal component analysis revealed that while the first principal component (global activity) and the second (reciprocal anteriorposterior activation) were similar in patients and controls, the third component (hemispheric reciprocity in activity) showed unique activation of the center versus anterior and posterior regions in patients with schizophrenia [163]. In a study on Autism Spectrum Disorder (ASD), autistic children exhibited longer P100 latencies, weaker N100 amplitudes and larger P300 amplitudes compared with typically developing (TD) children. [164]. ERPs detected in the early phase following traumatic brain injury have been found to serve as predictive markers for functional and cognitive recovery at six months post-injury [165]. ERPs have also been used to identify impairment in the dorsolateral prefrontal and anterior cingulate cortices in Parkinson's Disease [166]. EEG (non-linear complexity) in combination with a neuropsychological assessment (Alzheimer's Disease Assessment Scale-cognitive: ADAS-Cog) and cardiovascular history assessment was also found to increase diagnostic accuracy from $80 \%$ to $92 \%$ for distinguishing between $\mathrm{AD}$, vascular dementia, mixed dementia, and MCI [82].

Specific cortical auditory evoked ERPs have also been used to identify sensitive period cutoffs for primary auditory cortical development in juvenile cochlear implant recipients [167]. Further, ERPs have been used to identify differential emotional processing based on responses to emotionally negative stimuli in veterans with PTSD [168]. A study of African American seniors has also found that EEG spectral power at rest with eyes closed during a One Card Back Learning test (OCL, memory) was able to differentiate those at-risk of MCI from those that were stable [32].

\section{Technological variants of EEG}

In more recent years, specialized types of EEG have been developed for specific functions. Each of these provide unique advantages for applications in research or in the clinic. This section discusses two of the most common of these recent EEG-based technologies, quantitative EEG and low resolution electromagnetic tomography. (Table 1).

\section{Quantitative EEG (qEEG)}

In Quantitative EEG (qEEG), EEG data is used to create 2-D topographical color-coded brain maps that reflect the $\mathrm{Z}$-scores obtained of the patient's brain functioning when compared to a normative reference database (Neuroguide, FDA research standard) (Figure 1C). The waves are then analyzed to determine their distribution, power, ratio, coherence and connectivity across the cerebral lobes [144-146]. A study on the use of qEEG to monitor and aid in the treatment of traumatic brain injury (TBI) confirmed that alpha power (AUC $=0.87$, $\mathrm{p}<0.01$ ) and variability of the relative fast theta power ( $\mathrm{AUC}=0.84$, $\mathrm{p}<0.01$ ) demonstrated high prognostic value [17]. qEEG was also shown to have clinical diagnostic value for viral encephalitis, exhibiting a higher level of detail and precision compared with EEG [27]. Unusually high theta activity in the frontal region and higher theta-to-beta activity is observed in ADHD [169]. A review of studies on Parkinson's disease (PD) found slowing EEG frequencies to be correlated with a decline of cognition with increase of spectral powers in delta and theta and a decrease in alpha, beta, and gamma activity in this disease setting. Topographically the occipital, parietal, and temporal lobes also showed higher correlation with the spectral changes observed in Parkinson's disease [170].

\section{Low resolution electromagnetic tomography (LORETA)}

In Low Resolution Electromagnetic Tomography (LORETA), [147-153] 2-D EEG data is converted into 3-D data to locate the

Table 1. EEG-based markers of brain/mental health

\begin{tabular}{|c|c|}
\hline EEG & $\begin{array}{l}\text { - Wave form characteristics } \\
\text { - } \quad \text { Peak frequency of the brain waves recorded } \\
\text { - Theta-Beta Power Ratio } \\
\text { - Clinical significance/relevance of a) Low peak frequency, b) High peak frequency }\end{array}$ \\
\hline $\begin{array}{l}\text { Evoked Potentials \& Event-related potentials } \\
\text { (ERPs) }\end{array}$ & $\begin{array}{l}\text { - Visual evoked potentials (VEP), Auditory evoked potentials } \\
\text { - } \quad \text { PRPs their mean and peak amplitude and latency across neuro- and mental disorders. } \\
\text { anterior negativity (ELAN). Error-related negativity (ERN), Late positive component (LPC), Lateralized readiness potential (LRP), } \\
\text { Mismatch negativity, N2pc, Bereitschaft's potential, Contingent negative variation (CNV), Somatosensory evoked potential, Visual } \\
\text { N1, ERP synchrony and ERP desynchrony. } \\
\text { - Odd ball paradigm, ERP: the P300 and the latency (in ms) } \\
\text { - Steady-state visual evoked potentials (SSVEPs), the brain responses to repetitive visual stimulation (RVS), } \\
\text { - Resting state EEG }\end{array}$ \\
\hline Frequency Analysis \& qEEG & $\begin{array}{l}\left.\text { - Absolute power (voltage, } \mathrm{P}=\mathrm{mV}^{2}\right) \text { in the patient's EEG database } \\
\text { - Relative power in a brain wave compared to the total power in a patient's EEG }(\theta / \theta+\beta+\alpha+\Delta) \\
\text { - } \text { Inter- and intra-hemisphere coherence, right-left hemisphere and front-back balance in power and symmetry } \\
\text { - } \text { Mean frequency of the patient's brain waves. } \\
\text { - Z-score value of the patient's raw scores compared with the normative database - their direction and magnitude of the difference } \\
\text { and their implications on brain health } \\
\text { - Appearance of the above variables if there is a local, focal, regional or generalized abnormality? }\end{array}$ \\
\hline SLORETA \& ELORETA & $\begin{array}{l}\text { - Source of the electrical activity from the electrode/channel/derivation located in the brain } \\
\text { - Which Brodmann areas in the brain are involved? } \\
\text { - What are their cytoarchitecture, histology and function? }\end{array}$ \\
\hline
\end{tabular}


source of the EEG waves on the cortical lobes. This in turn identifies the functional areas involved, localizing wave responses to the source to provide a neuroanatomical context (Figure 1D).

In a case study of ADHD investigating treatment with dopamine agonist KB200z, LORETA was used to successfully identify increased in frequency bands in the anterior, dorsal and posterior cingulate regions and right dorsolateral prefrontal cortex in response to treatment. Another study used LORETA to demonstrate increased dissociation between brain processes in schizophrenic patients, a key factor thought to account for the differences in the cognitive and emotional state of schizophrenic patients [98]. Specific LORETA parameters (current phase density and lagged phase synchronization) have also been successfully correlated with $\mathrm{A} \beta 42$ and total tau concentration in Alzheimer's disease patients. A LORETA $z$-score feedback approach has also been shown to reduce pain in head and neck cancer patients, improvements associated with modified brain activity in pain-associated brain regions. In another study comparing healthy individuals with patients with treated and untreated menopausal syndrome and depression, LORETA was used to successfully identify cortical anatomical correlates of depression as well as the pharmacotherapy mode of action. LORETA was also able to identify significant elevations in alpha activity in the precuneus, and posterior middle temporal gyrus and decreased alpha activity in the medial frontal cortex, including the anterior cingulate and the superior and medial frontal gyri, in migraine patients.

\section{Conclusion}

The EEG has evolved in recent decades from a noninvasive monitoring tool into an instrument with diagnostic, prognostic and therapeutic/neurofeedback applications for neurological and mental disorders. Today's state-of-the-art EEG machines allow for spectral analysis using QEEG, and source analysis using LORETA. EEG-based technologies have also proven useful in the diagnosis of disorders with complex etiology and in the early diagnosis of cognitive impairment, providing clinicians with a valuable window of opportunity to implement preventive measures via lifestyle changes and/or therapeutic interventions. Today's state-of-the-art EEG machines, like NeuralScan by Medeia can perform tests with high accuracy within 15 minutes. Portability of current EEG machines allow for ease-of-use in public health and laboratory settings, as well as for research purposes and clinical use.

\section{Authorship and contributions}

$\mathrm{PM}, \mathrm{CC}, \mathrm{JL}, \mathrm{MA}$, and SD all contributed equally to the writing, review, and approval of this manuscript.

\section{Funding information}

This study was supported by internal funds from Medeia Inc. (SD) and Department of Surgery, University of California, Irvine. (PM, CC, JL, MA).

\section{Conflicts of interest}

One author is employed by Medeia, Inc. that produces NeuralScan.

\section{References}

1. Whiteford HA, Ferrari AJ, Degenhardt L, Feigin V, Vos T (2015) The global burden of mental, neurological and substance use disorders: an analysis from the Global Burden of Disease Study 2010. PLoS One 10: e0116820. [Crossref]

2. Khoury MJ, Gwinn M, Ioannidis JP (2010) The emergence of translational epidemiology: from scientific discovery to population health impact. Am J Epidemiol 172: $517-524$
3. Michel CM, Murray MM (2012) Towards the utilization of EEG as a brain imaging tool. Neuroimage 61: 371-385. [Crossref]

4. Jamal W, Das S, Maharatna K (2013) Existence of millisecond-order stable states in time-varying phase synchronization measure in EEG signals. In 2013 35th Annual International Conference of the IEEE Engineering in Medicine and Biology Society (EMBC) pp: 2539-2542.

5. Khanna A, Pascual-Leone A, Michel CM, Farzan F (2015) Microstates in resting-state EEG: current status and future directions. Neuroscience \& Biobehavioral Reviews 49: $105-13$.

6. Ney JP, van der Goes DN, Nuwer MR, Nelson L, Eccher MA (2013) Continuous and routine EEG in intensive care: utilization and outcomes, United States 2005-2009. Neurology 81: 2002-2008. [Crossref]

7. Kinney MO, Kaplan PW (2017) An update on the recognition and treatment of nonconvulsive status epilepticus in the inten sive care unit. Expert Rev Neurother 17: $987-$ 1002. [Crossref]

8. Caricato A, Melchionda I, Antonelli M (2018) Continuous electroencephalography monitoring in adults in the intensive care unit. Critical Care 22:75.

9. Claassen J, Mayer SA, Kowalski RG, Emerson RG, Hirsch LJ (2004) Detection of electrographic seizures with continuous EEG monitoring in critically ill patients. Neurology 62: 1743-1748.

10. Smith SJ (2005) EEG in the diagnosis, classification, and management of patients with epilepsy. Journal of Neurology, Neurosurgery \& Psychiatry 76: 2-7.

11. Laccheo I, Sonmezturk H, Bhatt AB, Tomycz L, Shi Y, et al. (2015) Non-convulsive status epilepticus and non-convulsive seizures in neurological ICU patients. Neurocritical care 22: 202-11.

12. Fogang Y, Legros B, Depondt C, Mavroudakis N, Gaspard N (2017) Yield of repeated intermittent EEG for seizure detection in critically ill adults. Clinical Neurophysiology 47: 5-12.

13. Ruiz AR, Vlachy J, Lee JW, Gilmore EJ, Ayer T, et al. (2017) Association of periodic and rhythmic electroencephalographic patterns with seizures in critically ill patients. JAMA neurology 74: 181-188.

14. Rapp PE, Keyser DO, Albano A, Hernandez R, Gibson DB, et al. (2015) Traumatic brain injury detection using electrophysiological methods. Frontiers in human neuroscience 9: 1-11.

15. Ulam F, Shelton C, Richards L, Davis L, Hunter B, et al. (2015) Cumulative effects of transcranial direct current stimulation on EEG oscillations and attention/working memory during subacute neurorehabilitation of traumatic brain injury. Clinical Neurophysiology 126: 486-96.

16. Curley WH, Forgacs PB, Voss HU, Conte MM, Schiff ND (2018) Characterization of EEG signals revealing covert cognition in the injured brain. Brain 141: 1404-1421.

17. Tolonen A, Särkelä MO, Takala RS, Katila A, Frantzén J, et al. (2018) Quantitative EEG parameters for prediction of outcome in severe traumatic brain injury: development study. Clinical EEG and neuroscience 49: 248-257.

18. Claassen J, Hirsch LJ, Kreiter KT, Du EY, Connolly ES, et al. (2004) Quantitative continuous EEG for detecting delayed cerebral ischemia in patients with poor-grade subarachnoid hemorrhage. Clinical neurophysiology 115: 2699-2710.

19. Diedler J, Sykora M, Bast T, Poli S, Veltkamp R, et al. (2009) Quantitative EEG correlates of low cerebral perfusion in severe stroke. Neurocritical care 11: 210-216.

20. Gollwitzer S, Groemer T, Rampp S, Hagge M, Olmes D, et al. (2015) Early prediction of delayed cerebral ischemia in subarachnoid hemorrhage based on quantitative EEG: a prospective study in adults. Clinical Neurophysiology 126: 1514-1523.

21. Gaspard N (2016) Current clinical evidence supporting the use of continuous EEG monitoring for delayed cerebral ischemia detection. Journal of Clinical Neurophysiology 33: 211-216.

22. Muniz CF, Shenoy AV, O'Connor KL, Bechek SC, Boyle EJ, et al, (2016) Clinical development and implementation of an institutional guideline for prospective EEG monitoring and reporting of delayed cerebral ischemia. Journal of clinical neurophysiology 33: 217 .

23. Rots ML, van Putten MJ, Hoedemaekers CW, Horn J (2016) Continuous EEG monitoring for early detection of delayed cerebral ischemia in subarachnoid hemorrhage: a pilot study. Neurocritical care 24: 207-216

24. Gollwitzer S, Müller TM, Hopfengärtner R, Rampp S, Merkel J, et al. (2019) Quantitative EEG After Subarachnoid Hemorrhage Predicts Long-Term Functional Outcome. Journal of Clinical Neurophysiology. 36: 25-31. 
25. Van Noord MU, Tecoma E, Kansal L, Karanjia N, Iragui-Madoz V (2016) Persistent EEG patterns in anti-NMDA receptor encephalitis: implications for pathophysiology.

26. Steriade C, Mirsattari SM, Murray BJ, Wennberg R (2016) Subclinical temporal EEG seizure pattern in LGI 1-antibody-mediated encephalitis. Epilepsia 57: e155-60.

27. Wu Y, Chen M, Cui Y, He X, Niu J, et al. (2018) Viral encephalitis in quantitative EEG. Journal of integrative neuroscience 1: 1-9.

28. Selvam VS, Devi SS (2015) Analysis of spectral features of EEG signal in brain tumor condition. Measurement Science Review 15: 219-225.

29. Awal MA, Lai MM, Azemi G, Boashash B, Colditz PB (2016) EEG background features that predict outcome in term neonates with hypoxic ischaemic encephalopathy: A structured review. Clinical Neurophysiology 127: 285-296.

30. Murray DM, O'Connor CM, Ryan CA, Korotchikova I, Boylan GB (2016) Early EEG grade and outcome at 5 years after mild neonatal hypoxic ischemic encephalopathy. Pediatrics 138: e20160659.

31. Weeke LC, Vilan A, Toet MC, van Haastert IC, de Vries LS, et al. (2017) Comparison of the Thompson encephalopathy score and amplitude-integrated EEG in infants with perinatal asphyxia and therapeutic hypothermia. Seizures and the Neonatal Brain 112:229.

32. Kavcic V, Zalar B, Giordani B (2016) The relationship between baseline EEG spectra power and memory performance in older African Americans endorsing cognitive concerns in a community setting. International Journal of Psychophysiology 109: 116123.

33. Kiiski H, Bennett M, Kelly C, Grogan K, Rai L, et al. (2017) EEG theta/beta ratio correlates positively with inattention and memory problems in ADHD and controls. European Neuropsychopharmacology. 27: 1102-1103.

34. Desjardins MÈ, Carrier J, Lina JM, Fortin M, Gosselin N, Montplaisir J, Zadra A. EEG functional connectivity prior to sleepwalking: evidence of interplay between sleep and wakefulness. Sleep 2017 40: 1-10.

35. Franzen PL, Buysse DJ (2017) Sleep in psychiatric disorders. In Sleep disorders medicine pp: 977-996.

36. Alvarez V, Sierra-Marcos A, Oddo M, Rossetti AO (2013) Yield of intermittent versus continuous EEG in comatose survivors of cardiac arrest treated with hypothermia. Critical care 17: R190.

37. Sandroni C, Cariou A, Cavallaro F, Cronberg T, Friberg H, et al. (2014) Prognostication in comatose survivors of cardiac arrest: an advisory statement from the European Resuscitation Council and the European Society of Intensive Care Medicine. Intensive care medicine. 40: 1816-1831.

38. Hofmeijer J, Beernink TM, Bosch FH, Beishuizen A, Tjepkema-Cloostermans MC, et al. (2015) Early EEG contributes to multimodal outcome prediction of postanoxic coma. Neurology 85: 137-43.

39. Zubler F, Steimer A, Kurmann R, Bandarabadi M, Novy J, et al. (2017) EEG synchronization measures are early outcome predictors in comatose patients after cardiac arrest. Clinical neurophysiology 128: 635-642.

40. Westhall E, Rossetti AO, van Rootselaar AF, Kjaer TW, Horn J, et al. (2016) Standardized EEG interpretation accurately predicts prognosis after cardiac arrest. Neurology 86: 1482-1490.

41. Szurhaj W, Lamblin MD, Kaminska A, Sediri H (2015) EEG guidelines in the diagnosis of brain death. Clinical Neurophysiology 45: 97-104.

42. Stecker MM, Sabau D, Sullivan LR, Das RR, Selioutski O, et al. (2016) American Clinical Neurophysiology Society guideline 6: minimum technical standards for EEG recording in suspected cerebral death. The Neurodiagnostic Journal 56: 276-284.

43. Babiloni C, Lizio R, Marzano N, Capotosto P, Soricelli A, et al. (2016) Brain neural synchronization and functional coupling in Alzheimer's disease as revealed by resting state EEG rhythms. International Journal of Psychophysiology 103: 88-102.

44. Shnitzer T, Yarovinsky N, Talmon R, Aharon-Peretz J (2018) EEG-based geometric modeling and analysis of cognitive deterioration in patients with possible and probable Alzheimer's disease Neurology. P:98.

45. Dauwan M, Van Dellen E, van Boxtel L, van Straaten EC, de Waal H, et al. (2016) EEG-directed connectivity from posterior brain regions is decreased in dementia with Lewy bodies: a comparison with Alzheimer's disease and controls. Neurobiology of aging 41: 122-129.

46. Yu M, Gouw AA, Hillebrand A, Tijms BM, Stam CJ, et al. (2016) Different functional connectivity and network topology in behavioral variant of frontotemporal dementia and Alzheimer's disease: an EEG study. Neurobiology of aging 42: 150-162.
47. Gschwind M, Hardmeier M, Van De Ville D, Tomescu MI, Penner IK, et al. (2016) Fluctuations of spontaneous EEG topographies predict disease state in relapsingremitting multiple sclerosis. NeuroImage: Clinical 12: 466-477.

48. Keune PM, Hansen S, Weber E, Zapf F, Habich J, et al. (2017) Exploring resting-state EEG brain oscillatory activity in relation to cognitive functioning in multiple sclerosis. Clinical Neurophysiology 128: 1746-1754.

49. Zipser CM, Premoli I, Castellanos N, Belardinelli P, Rivolta D, et al. (2018) Cortica excitability and interhemispheric connectivity in early relapsing-remitting multiple sclerosis studied with TMS-EEG. Frontiers in neuroscience 12: 393.

50. Camfferman D, Moseley GL, Gertz K, Pettet MW, Jensen MP (2017) Waking EEG Cortical Markers of Chronic Pain and Sleepiness. Pain Med 18: 1921-1931. [Crossref]

51. Fallon N, Chiu Y, Nurmikko T, Stancak A (2018) Altered theta oscillations in resting EEG of fibromyalgia syndrome patients. European journal of pain 22: 49-57.

52. Caviness JN, Hentz JG, Belden CM, Shill HA, Driver-Dunckley ED, et al. (2015) Longitudinal EEG changes correlate with cognitive measure deterioration in Parkinson's disease. Journal of Parkinson's disease. 5: 117-124.

53. Geraedts VJ, Marinus J, Gouw AA, Mosch A, Stam CJ, et al. (2018) Quantitative EEG reflects non-dopaminergic disease severity in Parkinson's disease. Clinical Neurophysiology 129: 1748-1755.

54. Güntekin B, Hanoglu L, Güner D, Yilmaz NH, Çadirci F, et al. (2018) Cognitive impairment in parkinson's disease is reflected with gradual decrease of EEG delta responses during auditory discrimination. Frontiers in psychology 9: 170.

55. Barcelon EA, Mukaino T, Yokoyama J, Uehara T, Ogata K, et al. (2019) Grand total EEG score can differentiate Parkinson's disease from Parkinson-related Disorders. Frontiers in Neurology 10: 398.

56. Akben SB, Tuncel D, Alkan A (2016) Classification of multi-channel EEG signals for migraine detection. Biomedical Research. 27: 743-748.

57. Porcaro C, Di Lorenzo G, Seri S, Pierelli F, Tecchio F, et al. (2017) Impaired brainstem and thalamic high-frequency oscillatory EEG activity in migraine between attacks. Cephalalgia 37: 915-926.

58. Cao Z, Lai KL, Lin CT, Chuang CH, Chou CC, et al. (2018) Exploring resting-state EEG complexity before migraine attacks. Cephalalgia 38: 1296-1306.

59. Snyder SM, Rugino TA, Hornig M, Stein MA (2015) Integration of an EEG biomarker with a clinician's ADHD evaluation. Brain Behav 5: e00330. [Crossref]

60. Rommel AS, James SN, McLoughlin G, Brandeis D, Banaschewski T, et al. (2017) Altered EEG spectral power during rest and cognitive performance: a comparison of preterm-born adolescents to adolescents with ADHD. European child \& adolescent psychiatry 26: 1511-1122.

61. Saad JF, Kohn MR (2018) Is the Theta/Beta EEG Marker for ADHD Inherently Flawed? J Atten Disord 22: 815-826. [Crossref]

62. Ewen JB, Lakshmanan BM, Pillai AS, McAuliffe D, Nettles C, et al. (2016) Decreased modulation of EEG oscillations in high-functioning autism during a motor control task. Frontiers in human neuroscience 10:198.

63. O'Reilly C, Lewis JD, Elsabbagh M (2017) Is functional brain connectivity atypical in autism? A systematic review of EEG and MEG studies. PLoS One 12: e0175870.

64. Bosl WJ, Tager-Flusberg H, Nelson CA (2018) EEG analytics for early detection of autism spectrum disorder: a data-driven approach. Scientific reports 8: 6828.

65. Allen JJ, Reznik SJ (2015) Frontal EEG asymmetry as a promising marker of depression vulnerability: Summary and methodological considerations. Current Opinion in Psychology 4: 93-97.

66. Acharya UR, Sudarshan VK, Adeli H, Santhosh J, Koh JE, et al. (2015) A nove depression diagnosis index using nonlinear features in EEG signals. European neurology 74: 79-83.

67. Arns M, Etkin A, Hegerl U, Williams LM, DeBattista C, et al. (2015) Frontal and rostral anterior cingulate (rACC) theta EEG in depression: Implications for treatment outcome?. European Neuropsychopharmacology 25: 1190-1200.

68. Lobo I, Portugal LC, Figueira I, Volchan E, David I, et al. (2015) EEG correlates of the severity of posttraumatic stress symptoms: a systematic review of the dimensional PTSD literature. Journal of Affective Disorders 183: 210-220.

69. Zhang Y, Toll R, Wu W, Longwell P, Shpigel E, et al. (2018) PTSD Subtype Identification Based on Resting-State EEG Functional Connectivity Biomarkers. Biological Psychiatry 83: S141. 
70. Zotev V, Phillips R, Misaki M, Wong CK, Wurfel BE, et al. (2018) Real-time fMRI neurofeedback training of the amygdala activity with simultaneous EEG in veterans with combat-related PTSD. NeuroImage: Clinical 19: 106-121.

71. Rahmani B, Wong CK, Norouzzadeh P, Bodurka J, McKinney B (2019) Correction: Dynamical Hurst analysis identifies EEG channel differences between PTSD and healthy controls. PloS one 14: e0214527.

72. Fisher SF, Lanius RA, Frewen PA (2016) EEG neurofeedback as adjunct to psychotherapy for complex developmental trauma-related disorders: Case study and treatment rationale. Traumatology 22: 255.

73. Fink BC, Steele VR, Maurer MJ, Fede SJ, Calhoun VD, et al. (2016) Brain potentials predict substance abuse treatment completion in a prison sample. Brain and behavior 6: $\mathrm{e} 00501$.

74. Tófoli LF, de Araujo DB (2016) Treating addiction: Perspectives from EEG and imaging studies on psychedelics. In International review of neurobiology Academic Press 129: 157-185

75. Laprevote V, Bon L, Krieg J, Schwitzer T, Bourion-Bedes S, et al. (2017) Association between increased EEG signal complexity and cannabis dependence. European Neuropsychopharmacology 27: 1216-1222.

76. Enriquez-Geppert S, Huster RJ, Herrmann CS (2017) EEG-Neurofeedback as a Tool to Modulate Cognition and Behavior: A Review Tutorial. Front Hum Neurosci 11:51

77. Bartholdy S, Musiat P, Campbell IC, Schmidt U (2013) The potential of neurofeedback in the treatment of eating disorders: a review of the literature. Eur Eat Disord Rev 21: 456-463. [Crossref]

78. Betty Jarusiewicz (2002) Efficacy of Neurofeedback for Children in the Autistic Spectrum: A Pilot Study. Journal of Neurotherapy 6: 39-49.

79. Sokhadze TM, Cannon RL, Trudeau DL (2008) EEG biofeedback as a treatment for substance use disorders: review, rating of efficacy, and recommendations for further research. Appl Psychophysiol Biofeedback 33:1-28.

80. Diaz BA, Sloot LH, Mansvelder HD, Linkenkaer-Hansen K (2012) EEG-Biofeedback as a tool to modulate arousal: trends and perspectives for treatment of ADHD and insomnia. Neuroimaging B 3: 431-451.

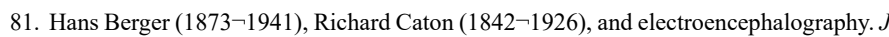
Neurol Neurosurg Psychiatry 74: 1-9. [Crossref]

82. Snyder SM, Hall JR, Cornwell SL, Falk JD (2011) Addition of EEG improves accuracy of a logistic model that uses neuropsychological and cardiovascular factors to identify dementia and MCI, Psychiatry Research 186: 97-102.

83. Cassani R, Estarellas M, San-Martin R, Fraga F, Falk T (2018) Systematic Review on Resting-State EEG for Alzheimer's Disease Diagnosis and Progression Assessment. Disease Markers 10: 1-26.

84. Babiloni C, Del Percio C, Caroli A, Salvatore E, Nicolai E, et al. (2016) Cortical sources of resting state EEG rhythms are related to brain hypometabolism in subjects with Alzheimer's disease: an EEG-PET study. Neurobiology of Aging 48: 122-134.

85. Smailovic U, Koenig T, Kåreholt I, Andersson T, Kramberger M, et al. (2018) Quantitative EEG power and synchronization correlate with Alzheimer's disease CSF biomarkers. Neurobiology of Aging 63: 88-95.

86. Poil S, de Haan W, van der Flier W, Mansvelder H, Scheltens P, et al. (2013) Integrative EEG biomarkers predict progression to Alzheimer's disease at the MCI stage. Frontiers in Aging Neuroscience 5: 1-10.

87. Newson JJ, Thiagarajan TC (2019) EEG Frequency Bands in Psychiatric Disorders: A Review of Resting State Studies. Front Hum Neurosci 12:521.

88. Khan H, Marcuse L, Fields M, Swann K, Yener B (2018) Focal Onset Seizure Prediction Using Convolutional Networks. IEEE Trans Biomed Eng 65: 2109-2118.

89. Jaitly R, Sgro JA, Towne AR, Ko D, DeLorenzo RJ (1997) Prognostic value of EEG monitoring after status epilepticus: a prospective adult study. J Clin Neurophysiol 14: 326-334. [Crossref]

90. Gatzonis S, Triantafyllou N, Kateri M, Siatouni A, Angelopoulos E, et al. (2010) The prognostic value of electroencephalography in epilepsy: a long-term follow-up study. Neurol Int 2: e18. [Crossref]

91. Gang Liu, Yingying Su, Yifei Liu (2016) Predicting outcome in comatose patients: the role of EEG reactivity to quantifiable electrical stimuli, Evid Based Complement Alternat Med [Crossref]
92. Rossetti AO, Urbano LA, Delodder F, Kaplan PW, Oddo M (2010) Prognostic value of continuous EEG monitoring during therapeutic hypothermia after cardiac arrest. Crit Care 14: R173.

93. Diaz BA, Hardstone R, Mansvelder HD, Van Someren EJ, Linkenkaer-Hansen K (2016) Resting-State Subjective Experience and EEG Biomarkers Are Associated with Sleep-Onset Latency. Front Psychol 7: 492.

94. C Zeman AZJ (2005) Neurological syndromes which can be mistaken for psychiatric conditions. J Neurol Neurosurg Psychiatry 76: i31-i38. [Crossref]

95. Chandra SR, Asheeb A, Dash S, Retna N, Ravi Teja KV, et al. (2017) Role of Electroencephalography in the Diagnosis and Treatment of Neuropsychiatric Border Zone Syndromes. Indian J Psychol Med 39: 243-249. [Crossref]

96. Smith SJM (2005) EEG in neurological conditions other than epilepsy: when does it help, what does it add? J Neurol Neurosurg Psychiatry 76: ii8-ii12.

97. Baird G, Santosh PJ (2003) Interface between neurology and psychiatry in childhood J Neurol Neurosurg Psychiatry 74: i17-i22.

98. Dietrich Lehmann, Pascal L Faber, Roberto D Pascual-Marqui, Patricia Milz, Werner M. Herrmann, et al. (2014) Functionally aberrant electrophysiological cortical connectivities in first episode medication-naive schizophrenics from three psychiatry centers. Front Hum Neurosci 8: 635.

99. Lopes da Silva F (2010) EEG: origin and measurement. In C. Mulert \& L. Lemieux (Eds.), EEG-fMRI: physiological basis, technique, and applications. London: Springer 1: $19-38$.

100. Lopez-Gordo MA, Sanchez-Morillo D, Pelayo Valle F (2014) Dry EEG electrodes. Sensors 14:12847-12870.

101. Yeung A, Garudadri H, Van Toen C, Mercier P, Balkan O, et al. (2015) Comparison of foam-based and spring-loaded dry EEG electrodes with wet electrodes in resting and moving conditions. Conf Proc IEEE Eng Med Biol Soc 2015: 7131-7134. [Crossref]

102. Ferree TC, Luu P, Russell GS, Tucker DM (2001) Scalp electrode impedance, infection risk, and EEG data quality. Clin Neurophysiol 112: 536-544. [Crossref]

103. Forvi E, Bedoni M, Carabalona R, Soncini M, Mazzoleni P, et al. (2012) Preliminary technological assessment of microneedles-based dry electrodes for biopotential monitoring in clinical examinations. Sens Actuators A Phys 180: 177-186.

104. Ruffini G, Dunne S, Fuentemilla L, Grau C, Farrés E, et al. (2008) First human trials of a dry electrophysiology sensor using a carbon nanotube array interface. Sens Actuators A Phys 144: 275-279.

105. Dias NS, Carmo JP, da Silva AF, Mendes PM, Correia JH (2010) New dry electrodes based on iridium oxide ( $\mathrm{IrO}$ ) for non-invasive biopotential recordings and stimulation. Sens Actuators A Phys 164: 28-34.

106. Lin CT, Liao LD, Liu YH, Wang IJ, Lin BS, et al. (2011) Novel dry polymer foam electrodes for long-term EEG measurement. IEEE Trans Biomed Eng 58: 1200-1207. [Crossref]

107. Sullivan TJ, Deiss SR, Cauwenberghs G (2007) A Low-Noise, Non-Contact EEG/ ECG Sensor. In Proceedings of the Biomedical Circuits and Systems Conference. Biocas pp: 154-157.

108. Nunez PL (2006) Srinivasan, R. Electric Fields of the Brain; Oxford University Press: Oxford, UK

109. Jurcak V, Tsuzuki D, Dan I (2007) 10/20, 10/10, and 10/5 systems revisited: their validity as relative head-surface-based positioningsystems. Neuroimage 34: 16001611.

110. Jasper HH (1958) The ten-twenty electrode system of the International Federation. Electroencephalogr Clin Neurophysiol 10: 367-380.

111. Jurcak V, Okamoto M, Singh A, Dan I (2005) Virtual 10-20 measurement on MR images for inter-modal linking of transcranial and tomographic neuroimaging methods. NeuroImage 26: 1184-1192.

112. Nuwer MR, Comi G, Emerson R, Fuglsang-Frederiksen A, Guerit JM, et al. (1998) IFCN standards for digital recording of clinical EEG. International Federation of Clinical Neurophysiology. Electroencephalogr Clin Neurophysiol 106: 259-261.

113. Herwig U, Satrapi P, Schonfeldt-Lecuona C (2003) Using the international 10-20 EEG system for positioning of transcranial magnetic stimulation. Brain Topogr 16: 95-99.

114. Myslobodsky MS, Coppola R, Bar-Ziv J, Weinberger DR (1990) Adequacy of the International 10-20 electrode system for computed neurophysiologic topography. $J$ Clin Neurophysiol 7: 507-518. 
115. Oostenveld R, Praamstra P (2001) The five percent electrode system for highresolution EEG and ERP measurements. Clin Neurophysiol 112: 713-719. [Crossref]

116. Chatrian GE, Lettich E, Nelson PL (1985) Ten percent electrode system for topographic studies of spontaneous and evoked EEG activity. Am J EEG Technol 25: 83-92.

117. Chatrian GE, Lettich E, Nelson PL (1988) Modified nomenclature for the "10\%" electrode system. J Clin Neurophysiol 5: 183-186. [Crossref]

118. Le J, Lu M, Pellouchoud E, Gevins A (1998) A rapid method for determining standard 10/10 electrode positions for high resolution EEG studies. Electroencephalogr Clin Neurophysiol 106: 554-558.

119. Acharya JN, Hani AJ, Thirumala PD, Tsuchida TN (2016) American Clinical Neurophysiology Society Guideline 3: A Proposal for Standard Montages to Be Used in Clinical EEG. J Clin Neurophysiol 33: 312-316.

120. American Clinical Neurophysiology Society (1994) Guideline 14: Guidelines for recording clinical EEG on digital media. J Clin Neurophysiol 11: 114-115.

121. Gorney D (1992) The practical guide to digital EEG. Am J EEG Technol 32: 260-289.

122. Teplan M (2002) Fundamental of EEG measurement article in measurement science review.

123. International Federation for Clinical Neurophysiology (1996) IFCN Digital EEG Standards Draft

124. Luders H (1991) EEG digitization: Format for storage and interlab transmission, Appendix B. In: Luders, H. (Ed.) Epilepsy Surgery, Raven Press, New York.

125. McLachlan R, Young GB (1999) Minimal standards for digital/quantitative electroencephalography in Canada. Can J Neurol Sci 26:153.

126. Wong P (1996) Digital EEG in Clinical Practice, Lippincott-Raven Publishers, New York.

127. Sinha SR, Sullivan L, Sabau D, San-Juan D, Dombrowski KE, et al. (2016) American clinical neurophysiology society guideline 1: Minimum technical requirements for performing clinical electroencephalography. J Clin Neurophysiol 33: 303-307.

128. Dash D, Dash C, Primrose S, Hernandez-Ronquillo L, Moien-Afshari F, et al. (2017) Update on Minimal Standards for Electroencephalography in Canada: A Review by the Canadian Society of Clinical Neurophysiologists. Can J Neurol Sci 44: 631-642.

129. International Organisation of Societies for Electrophysiological Technology (OSET) Guidelines for digital eeg. Commission 1995-1999. Available www.oset.org/ Guidelines_files/GuidesDigitalEEGforOSETJG1299RTF\%5B1\%5D.doc

130. Urigüen JA, Garcia-Zapirain B (2015) EEG artifact removal-state-of-the-art and guidelines. J Neural Eng 12: 031001. [Crossref]

131. Al-Qazzaz NK, Hamid Bin Mohd Ali S, Ahmad SA, Islam MS, Escudero J (2017) Automatic Artifact Removal in EEG of Normal and Demented Individuals Using ICA-WT during Working Memory Tasks. Sensors pii: E1326.

132. Jiang X, Bian GB, Tian Z (2019) Removal of Artifacts from EEG Signals: A Review. Sensors (Basel) 19. [Crossref]

133. Al-Fahoum AS, Al-Fraihat AA (2014) Methods of EEG signal features extraction using linear analysis in frequency and time-frequency domains. ISRN Neurosci. [Crossref]

134. AR. Mane, Biradar SD, Shastri RK (2015) Review paper on Feature Extraction Methods for EEG Signal Analysis. International Journal of Emerging Trend in Engineering and Basic Sciences 2: 545-552.

135. Nandish M, Michahial S, Kumar P, Ahmed F (2012) Feature extraction and classification of eeg signal using neural network based techniques. International Journal of Engineering and Innovative Technology 2.

136. Wen T, Zhang Z (2017) Effective and extensible feature extraction method using genetic algorithm-based frequency-domain feature search for epileptic EEG multiclassification. Medicine (Baltimore). 96: e6879.

137. Zakir Hossain, Monirul Kabir, Shahjahan (2013) Feature Selection of EEG data with Neuro-Statistical Method. International Conference on Electrical Information and Communication technology.

138. Puce A, Hämäläinen MS (2017) A Review of Issues Related to Data Acquisition and Analysis in EEG/MEG Studies. Brain Sci 7. [Crossref]
139. Mumtaz W, Xia L, Mohd Yasin MA, Azhar Ali SS, Malik AS (2017) A wavelet-based technique to predict treatment outcome for Major Depressive Disorder. PLoS One 12: $\mathrm{e} 0171409$.

140. R Sucholeik (2017) Normal EEG Waveforms. Available from: https://emedicine medscape.com/article/1139332-overview

141. Britton JW, Frey LC, Hopp JL (2016) Electroencephalography (EEG): An Introductory Text and Atlas of Normal and Abnormal Findings in Adults, Children, and Infants. In St. Louis EK, Frey LC (Eds.,). Chicago: American Epilepsy Society

142. Kane N, Acharya J, Benickzy S (2017) A revised glossary of terms most commonly used by clinical electroencephalographers and updated proposal for the report format of the EEG findings. Revision. Clin Neurophysiol Pract 2: 170-185.

143. 30 Years of Accepted Science of the NeuroGuide Normative Databases. Available from: https://www.appliedneuroscience.com/PDFs/30_Years_of_Accepted Science_of_the_NeuroGuide_Normative_Databases.pdf

144. Thatcher RW, Lubar JF (2008) History of The Scientific Standards of QEEG Normative Databases. Published in: "Introduction to QEEG and Neurofeedback: Advanced Theory and Applications" Thomas Budzinsky, H. Budzinski, J. Evans and A. Abarbanel editors, Academic Press, San Diego, CA.

145. Summary FDA Available from: www.accessdata.fda.gov/cdrh docs/pdf4/K041263 pdf

146. Pascual Marqui RD, Lehmann D, Koukkou M, Kochi K, Anderer P, et al. (2011) Assessing interactions in the brain with exact low-resolution electromagnetic tomography. Philos. Trans A Math Phys Eng Sci 369: 3768-3784.

147. Pascual-Marqui RD (2007) Discrete, 3D distributed, linear imaging methods of electric neuronal activity. Part 1: exact, zero error localization. arXiv:0710.3341.

148. Pascual-Marqui, Pascual-Montano AD, Lehmann D, Kochi K, Esslen M, et al. (2006) Exact low resolution brain electromagnetic tomography (eLORETA). Neuroimage 31: $\mathrm{S} 86$

149. Pascual-Marqui RD, Esslen M, Kochi K, Lehmann D (2002) Functional imaging with low-resolution brain electromagnetic tomography (LORETA): a review. Methods Find. Exp Clin Pharmacol 24: 91-95.

150. Pascual-Marqui RD1 (2002) Standardized low-resolution brain electromagnetic tomography (sLORETA): technical details. Methods Find Exp Clin Pharmacol 24 5-12. [Crossref]

151. Pascual-Marqui (1999) Review of methods for solving the EEG inverse problem. International Journal of Bioelectromagnetism 1:75-86.

152. Pascual-Marqui RD1, Michel CM, Lehmann D (1994) Low resolution electromagnetic tomography: a new method for localizing electrical activity in the brain. Int J Psychophysiol 18: 49-65. [Crossref]

153. CA Richardson et al. Generalized EEG Waveform Abnormalities. Available from https://emedicine.medscape.com/article/1140075-overview

154. Mekki M, Eley B, Hardie D, Wilmshurst JM (2019) Subacute sclerosing panencephalitis: clinical phenotype, epidemiology, and preventive interventions. Developmental Medicine \& Child Neurology.

155. Morabito FC, Campolo M, Mammone N, Versaci M, Franceschetti S, et al (2017) Deep learning representation from electroencephalography of early-stage Creutzfeldt-Jakob disease and features for differentiation from rapidly progressive dementia. International journal of neural systems 27: 1650039

156. Sur S, Sinha VK (2009) Event-related potential: An overview. Ind Psychiatry J 18 : 70-73. [Crossref]

157. Woodman GF (2010) A brief introduction to the use of event-related potentials in studies of perception and attention. Atten Percept Psychophys 72: 2031-2046.

158. Horvath A, Szucs A, Csukly G, Sakovics A, Stefanics G, et al. (2018) EEG and ERP biomarkers of Alzheimer's disease: a critical review. Front Biosci 23: 183-220.

159. Tanaka S, Maezawa Y, Kirino E (2013) Classification of Schizophrenia Patients and Healthy Controls Using P100 Event-Related Potentials for Visual Processing. Neuropsychobiology 68: 71-78.

160. Wang S, Yang C, Liu Y, Shao Z, Jackson T (2017) Early and late stage processing abnormalities in autism spectrum disorders: An ERP study. Plos one 12: 0178542.

161. Hauger SL, Olafsen K, Schnakers C, Andelic N, Nilsen KB, et al. (2017) Cognitive event-related potentials during the sub-acute phase of severe traumatic brain injury and their relationship to outcome. Journal of neurotrauma. 34: 3124-3133. 
162. Bocquillon P, Bourriez JL, Palmero-Soler E, Defebvre L, Derambure P, et al. (2015) Impaired early attentional processes in Parkinson's disease: a high-resolution eventrelated potentials study. PloS one 10: e0131654.

163. Sharma A, Campbell J, Cardon G (2015) Developmental and cross-modal plasticity in deafness: Evidence from the P1 and N1 event related potentials in cochlear implanted children. International Journal of Psychophysiology 95: 135-144.

164. Fitzgerald JM, MacNamara A, DiGangi JA, Kennedy AE, Rabinak CA, et al. (2016) An electrocortical investigation of voluntary emotion regulation in combat-related posttraumatic stress disorder. Psychiatry Research: Neuroimaging 249: 113-121.

165. Cozac VV, Gschwandtner U, Hatz F, Hardmeier M, Rüegg S1, et al. (2016) Quantitative EEG and Cognitive Decline in Parkinson's Disease. Parkinsons Dis 2016: 9060649. [Crossref]

166. Steinberg B, Blum K, McLaughlin T (2016) Low-Resolution Electromagnetic Tomography (LORETA) of changed Brain Function Provoked by Pro-Dopamine Regulator (KB220z) in one Adult ADHD case. Open J Clin Med Case Rep 2:1121.
167. Hata M, Tanaka T, Kazui H, Ishii R, Canuet L, et al. (2017) Cerebrospinal fluid biomarkers of Alzheimer's disease correlate with electroencephalography parameters assessed by exact low-resolution electromagnetic tomography (eLORETA). Clinical EEG and neuroscience 48: 338-347.

168. Prinsloo S, Rosenthal DI, Lyle R, Garcia SM, Gabel-Zepeda S, et al. (2019) Exploratory study of low resolution electromagnetic tomography (LORETA) realtime z-score feedback in the treatment of pain in patients with head and neck cancer. Brain topography 32: 283-285.

169. Saletu B, Anderer P, Saletu-Zyhlarz GM (2010) EEG topography and tomography (LORETA) in diagnosis and pharmacotherapy of depression. Clin EEG Neurosci 41: 203-210. [Crossref]

170. Clemens B, Bánk J, Piros P, Bessenyei M, Veto S, et al. (2008) Three-dimensional localization of abnormal EEG activity in migraine: a low resolution electromagnetic tomography (LORETA) study of migraine patients in the pain-free interval. Brain Topogr 21: 36-42.

Copyright: (C2019 Miranda P. This is an open-access article distributed under the terms of the Creative Commons Attribution License, which permits unrestricted use, distribution, and reproduction in any medium, provided the original author and source are credited. 